\title{
Leveraging the value of online data and methods: Drug policy research at the cutting edge
}

DOI:

10.1016/j.drugpo.2019.09.005

\section{Document Version}

Final published version

Link to publication record in Manchester Research Explorer

\section{Citation for published version (APA):}

Aldridge, J., \& Bouchard, M. (2019). Leveraging the value of online data and methods: Drug policy research at the cutting edge. International Journal of Drug Policy. https://doi.org/10.1016/j.drugpo.2019.09.005

\section{Published in:}

International Journal of Drug Policy

\section{Citing this paper}

Please note that where the full-text provided on Manchester Research Explorer is the Author Accepted Manuscript or Proof version this may differ from the final Published version. If citing, it is advised that you check and use the publisher's definitive version.

\section{General rights}

Copyright and moral rights for the publications made accessible in the Research Explorer are retained by the authors and/or other copyright owners and it is a condition of accessing publications that users recognise and abide by the legal requirements associated with these rights.

\section{Takedown policy}

If you believe that this document breaches copyright please refer to the University of Manchester's Takedown Procedures [http://man.ac.uk/04Y6Bo] or contact uml.scholarlycommunications@manchester.ac.uk providing relevant details, so we can investigate your claim.

\section{OPEN ACCESS}


Editorial

\section{Leveraging the value of online data and methods: Drug policy research at the cutting edge}

Is the online domain really so terribly important for drug policy researchers to engage with in order to study drugs and drug policy? Is illicit drug use not, after all, an 'offline' activity enacted by people with their offline identities as they buy, sell and consume - not digital - but physical psychoactive substances? With this special section of International Journal of Drug Policy, we aim to persuade readers of the importance of the internet and other digital technologies in generating research aimed at understanding the people who use illicit drugs, in understanding illicit drug supply, and for devising and evaluating effective drug policies. In doing so, we introduce a series of articles by researchers using online data and methods that enable them to gain fresh drug policy-relevant insights. Many of these insights, we argue, would not otherwise be possible using traditional research methods and data sources. All articles from this special section originated from presentations made at the 12th annual conference of the International Society for the Study of Drug Policy (ISSDP) held in Vancouver, in May 2018.

While it would be foolish to present online data and methods as ideally suited to all empirical drug policy research, we nonetheless suspect these may be under-utilised. By way of illustration, of the 119 papers presented at the 2018 conference of the ISSDP that reported the results of empirical research, only $8 \%$ used online methods for data collection such as web surveys, and $12 \%$ collected topic-relevant data from online websites that researchers themselves did not solicit, such as drug discussion forums. There may well therefore be scope for researchers to exploit more fully 'unsolicited' online data, or to use the internet to facilitate the collection of primary data with drug policy relevance.

Policy makers are increasingly urged to recognize the importance of listening to the voices of people who use drugs themselves to inform policy development, interventions and education directly affecting those same people (Lancaster, Santana \& Madden, 2015). But locating and gaining the trust of people with 'lived experience' of drug use can be challenging, particularly if those seeking out these voices represent the agencies associated with officialdom, or are perceived to be. Social stigma and the threat of legal sanction together make people who use illegal drugs wary of making frank disclosures; the voices of these 'hidden' populations can often remain unheard. As Enghoff and Aldridge (this issue) show, the internet has enabled people who use drugs to form online communities for support, debate, and knowledge sharing, for example in connection to harm reduction practices. The 'digital traces' (see Décary-Hétu \& Aldridge, 2015) these online communities produce, when collected by researchers and then used as data, are referred to by Enghoff and Aldridge as 'unsolicited' by those researchers. Unsolicited online data therefore can complement understanding about people who use drugs derived from traditional research methods like surveys and interviews.

\section{Making less accessible populations available to researchers}

Stigma and the risk of legal sanction connected to drug supply activities - by comparison to drug possession/use - are even more heightened, and may make the voices of illegal drug sellers comparatively inaccessible to researchers. Three of the articles in this issue used online technologies successfully to gain access to individuals participating in online drug markets. Kamphausen and Werse (this issue) collected unsolicited data derived from cryptomarket (aka 'darknet market') discussion forums to examine the security measures drug sellers use to reduce the risk of detection by law enforcement and losses resulting from marketplace scams. Kowalski and colleagues (this issue) similarly collected data from cryptomarket discussion forums to better understand the barriers to more widespread use of cryptomarkets: the challenges users face in acquiring necessary technical know-how. Even tried-and-tested traditional qualitative research methods like in-depth interviews, when conducted in virtual space, can facilitate access to this hard-to-reach group. Bakken and Demant (this issue) conducted 107 interviews with 'social media drug dealers' to understand their risk perceptions. The researchers cleverly conducted their online interviews using the very same encrypted chat app (Wickr) these dealers used for their drug selling, and therefore already trusted to ensure their anonymity. With each of these three papers, we see that online research methods not only enabled access to an otherwise difficult-to-access population, but simultaneously shed light on the increasing importance of internet-facilitated spaces to illegal drug trading.

\section{Identifying new trends in drug markets}

We are witnessing unprecedented change connected to illegal drugs across the globe. Significant shifts are occurring in the types of drugs used, including an influx of entirely new substances, alongside developments in the ways drugs are consumed, and innovations in how they are bought and sold. It is increasingly challenging for state and civil society agencies to stay abreast of developments in order to devise appropriately informed and effective health, criminal justice and educational policies and interventions. Research using online data and methods can be especially valuable for identifying new developments and for charting trends. Rhumorbarbe and colleagues used data derived from an online drug forum to identify discussion about new or novel psychoactive substances (NPS), which the authors found in many cases pre-dated the first notification to the official European 'early warning' system. The authors also devised an indicator of discussion intensity related to a particular substance that can be used to track trends in substance popularity. Cunliffe and colleagues (this issue) also used unsolicited online data to track cryptomarket sales of sedative and stimulant prescription medications over a three-year period. The 
authors identify an upward trend in sales of alprazolam (brand name Xanax), consistent with increased reports of its growing problem use in some countries. Interestingly, the authors suggest that cryptomarket sales data is likely to provide insights into illicit drug markets more widely. To the extent that cryptomarket selling mirrors wider drug market patterns, the potential for this unsolicited online data to drug policy scholars for supply and demand-side drug monitoring is even more valuable.

\section{Overcoming some of the limitations of traditional methods}

This special issue contains additional examples of how online data collection may help complement the data obtained through traditional methods. For Bancroft (this issue) the scale and reach of the annual Global Drug Survey (the GDS's 2019 survey returned 168,000 responses from participants in 20 countries) is made possible only because data collection is online. While expensive, state-sponsored population surveys using probability sampling methods are deemed the gold-standard in generating representative samples for identifying the prevalence of drug use in the population, they are limited in capturing relatively small numbers of people who use drugs, about which only limited information can be collected. Bancroft suggests that success of the GDS in producing unprecedentedly detailed and valuable understanding of drug using behaviours via its web survey approach challenges traditional scientific hierarchies of value connected to particular research methods.

With increasing recognition that web surveys like the GDS transcend some of the limitations of general population surveys, it may be no surprise that state agencies might seek to supplement their traditional drug monitoring data sources with web surveys. Matias and colleagues (this issue) describe the pilot development of the new European Web Survey on Drugs (EWSD) by the EMCDDA implemented in 14 European countries, and report some of its results and methodological issues. The authors conclude that the EWSD fills important gaps in understanding, particularly in connection to recreational drug use. A second paper in this issue by Skarapova and colleagues reports the results of reliability and comprehensibility testing for some EWSD questions. The EWSD is a potentially important development in drug monitoring. It will be interesting to contrast its results to those produced by the long-established GDS, which by comparison to the EWSD, is independently-funded and explicitly aims to produce and share drug harm reduction knowledge.

We urge researchers not just to consider the value of online data and methods, but to attend carefully to the centrality of the digital social world in understanding drug-related behaviours, beliefs and policies. Lewis and Snitzman (this issue) used an online survey to reach over 600 Israeli adults who were asked about their opinion on a range of drug policy issues, including cannabis legalization. Of note, the authors also asked users whether they obtained their information through online or traditional mass media sources, and whether the source made a difference in their opinion. It did, though the path is indirect: respondents who sought information on cannabis online were more likely to have favorable attitudes towards medical cannabis which, in turn, had a positive impact on their attitudes towards legalization.

\section{Concluding thoughts}

We are observing a rapid pace-of-change not just in drug use and supply patterns and trends, but also in connection to drug policies themselves, with governments in countries across the globe experimenting with new laws and regulatory frameworks in a bid to more effectively address these phenomena. Here too, online data and methods offer researchers fresh opportunities for drug policy evaluation. Enghoff and Aldridge (this issue) highlight the unique importance of cryptomarket data for identifying increases or decreases in sales of particular substances in illicit drug markets over time. Importantly, and because data collected online from drug cryptomarket transactions is dated, longitudinal cryptomarket datasets effectively provides us with a window on the changing size of illicit drug market buying and selling. Changes in drug markets may be detected more swiftly, and trends be monitored more effectively. We might, optimistically, expect drug policies to follow suit, and react more quickly to a changing drug market landscape. At the same time, the focus on online data and markets limits scholars in the geographical locations and populations they access. Online research runs the risk perpetuating the dominance of developed nations in drug policy research, an issue we hope scholars will remain sensitive to, especially in monitoring trends, or estimating the size and reach of these markets.

Demarcating private from private spaces in the online world is not always straightforward, and not all online and social media data that can be collected by researchers should be. The use of online data and methods by drug policy scholars, therefore, carries with it fresh ethical and political challenges, with which authors in this issue have had to contend. There is a growing methodological literature around online methods that addresses ethical issues emerging from across a wide range of discipline areas (e.g. Chiauzzi \& Wicks, 2019) that drug policy researchers can turn to for guidance. Enghoff and Aldridge (this issue) review some of this literature, but ways forward are by no means clear, and there is as yet little consensus on ethical research practice in the online domain. As one example, Bancroft (this issue) encourages us to consider whether online methods require researchers to consider a new concept of subject identity worthy of protection that includes pseudonymous online profiles.

Drug policy researchers are exceptionally well-placed to reap the rewards offered by online data and methods, enabling them to generate insights unavailable using other methods. Drug researchers have long been at the forefront of methodological innovation, for example in accessing hard-to-reach populations. Drug policy scholarship can and should continue to make leading contributions to the inter-disciplinary methodological literature that drives innovations in the use of online data and methods while, at the same time, seeking to guide others in using these approaches ethically and responsibly.

\section{Declaration of Competing Interest}

None to declare.

\section{References}

Chiauzzi, E., \& Wicks, P. (2019). Digital trespass: Ethical and terms-of-use violations by researchers accessing data from an online patient community. Journal of Medical Internet Research, 21, E11985.

Décary-Hétu, D., \& Aldridge, J. (2015). Sifting through the net: Monitoring of online offenders by researchers. European Review of Organised Crime, 2(2), 122-141.

Lancaster, K., Santana, L., Madden, A., et al. (2015). igma and subjectivities: Examining the textured relationship between lived experience and opinions about drug policy among people who inject drugs. Drugs: Education, Prevention and Policy, 22, 224-231.

Judith Aldridge $\mathrm{a}^{\mathrm{a}, *}$, Martin Bouchard ${ }^{\mathrm{b}}$

a Department of Criminology, University of Manchester, Oxford Road, Manchester M13 9PL, United Kingdom

${ }^{\mathrm{b}}$ School of Criminology, Simon Fraser University, 8888 University Drive, Burnaby, BC V5A 1S6, Canada

E-mail addresses: judith.aldridge@manchester.ac.uk (J. Aldridge), mbouchard@sfu.ca (M. Bouchard).

* Corresponding author. 